\title{
Immobilized Polythiophene-fullerene on Surfaces: Beyond Photovoltaics $\dagger$
}

\author{
Periyamuthu Ramar, ${ }^{\mathrm{a}, \mathrm{b}}$ B.V. Aishwarya ${ }^{\mathrm{a}}$ and Debasis Samanta ${ }^{\mathrm{a}, \mathrm{b}}$ \\ a Periyamuthu Ramar, B.V. Aishwarya, Dr.Debasis Samanta, Polymer Science and Technology Department, CSIR- Central Leather Research Institute \\ Chennai, India, E-mail:debasis@clri.res.in \\ b Periyamuthu Ramar, Dr.Debasis Samanta, Academy of Scientific and innovative research, Ghaziabad, uttarpradesh, india
}

\begin{abstract}
Surfaces coated with polythiophene-fullerene, particularly poly(3-hexylthiophene)-Phenyl-C61-butyric acid methyl ester (P3HTPCBM) emerged as a gold standard for fabrication of photovoltaic devices of bulk heterojunction type. Since, photocatalytic dye degradation has a similar initiation mechanism driven by electron-hole production under sunlight, the surface was used as a reusable photocatalytic "chip" to degrade polluting organic dyes. Detailed investigations were carried out on various factors affecting the efficacy.
\end{abstract}

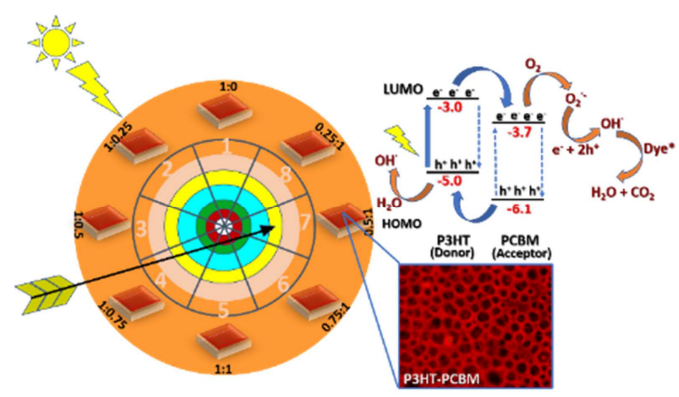

Polymer-immobilized surfaces have different applications ranging from sensors to photovoltaic devices. ${ }^{1-3}$ Particularly, different polymers along with other materials have been immobilized on surfaces by spin coating, ${ }^{4}$ drop casting ${ }^{5}$, or self-assembled monolayer formation ${ }^{6}$ for the application as bulk heterojunction solar cell devices. In this context, The most studied $^{7}$ polymeric photovoltaic devices have been fabricated by immobilization of poly(3-hexylthiophene)-Phenyl- $\mathrm{C}_{61}$-butyric acid methyl ester (P3HT-PCBM) as a donor-acceptor system on buffer coating to an ITO surface. ${ }^{8-12}$ This was frequently used to optimize different parameters for best power conversion efficiency. The concentration ratio of $\mathrm{P} 3 \mathrm{HT}$ and $\mathrm{PCBM}$ is one of such important parameters. In this context, two conflicting phenomenon plays important role: as PCBM concentration increases, the amplified exciton dissociation at the bulk heterojunction leads to increased polaron lifetime, while, an increased concentration can also lead to the localization of polarons significantly affecting the efficiency. ${ }^{13}$ It was found by several researchers that although the concentration ratio of $0.5: 1$ for P3HTPCBM systems provides one of the highest open-circuit voltage $\left(\mathrm{V}_{\mathrm{OC}}\right)$, power conversion efficiency increases manifold when the concentration ratio is increased. ${ }^{14}$ For example Hassan and others observed that the best performance was observed when P3HT:PCBM ratio is $3: 1 .^{15}$ On the other hand, under slightly different conditions, best efficacy was observed in a ratio of 1:0.8 to $1.1 .^{17,18}$ The exact reason is still debatable, conclusions were drawn from microscopic studies that well defined interfaces between regions help charge separations ${ }^{19}$ while SAXS studies indicated "instead this is a more complicated system incorporating regions of crystalline P3HT, PCBM, and intermixed regions of amorphous P3HT and PCBM". ${ }^{20}$ In both the cases, improved efficiency in bulk heterojunction solar cell can be attributed to the effectiveness of transportation of charges to the respective electrodes; which can also be facilitated by the presence of excess conductive polymers.

It was recognized that semiconductor-based polymer photocatalysts $^{21-25}$ have a similar mechanism of generation of electrons/holes under sunlight which promote the generation of various free radicals leading to degradation of organic dyes locally, without the involvement of transportation of charges (Figure 1(a) and 1(b) respectively). ${ }^{26-29}$ Bahers et al and others reported that ${ }^{30-32}$ the light absorption and exciton dissociation processes were similar in both cases of photovoltaics and photocatalysis. In photovoltaics, the current was generated by diffusion of free charge carriers to the electrodes while in the case of photocatalysis, without electrodes the resulting electron and holes were diffused to the catalysts sites and reacted directly with $\mathrm{O}_{2}$ and $\mathrm{H}_{2} \mathrm{O}$ molecules to generate various radical species which can degrade the dye molecules. ${ }^{33,}{ }^{34}$ since photocatalysis involves the generation of charges in presence of sunlight but not the transportation of charges only a few localized factors like morphology or concentration ratios can play more important role to improve efficacy compared to photovoltaic devices (ESI table S7). Although research efforts were undertaken to improve the efficacy of the polymeric solar cell devices ${ }^{35-38}$ and/or finding, a correlation with composition, morphology and mobility of electrons/holes ${ }^{4,14,39}$ to the best of our knowledge, this is the first attempt to study in detail the efficacy of P3HT-PCBM based reusable photocatalytic device in the form of a chip.

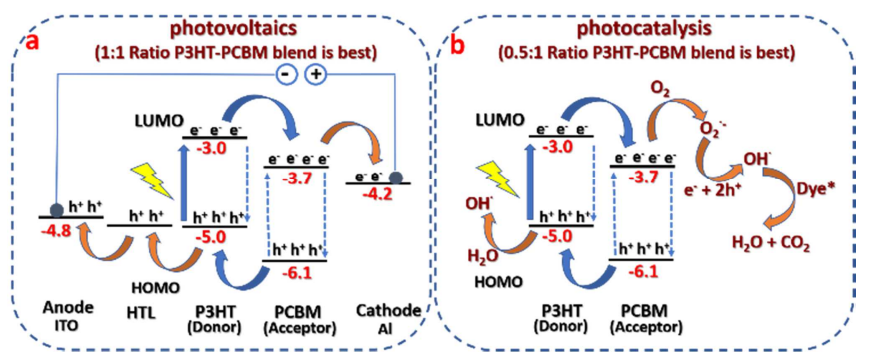

Figure 1. Schematic representation of (a) sunlight driven generation and transportation of electrons and holes in photovoltaics (bulk heterojunction) and (b) sunlight driven generation of electrons and holes followed by the production of active radical species in photocatalysis.

The study of donor/acceptor surface interfacial properties and surface morphology are very powerful tools for understanding the alteration of system efficiencies. ${ }^{40}$ Since, the fluorescent properties of donor/acceptor components in solution as well as blend form indirectly provides information about efficiency and the properties of heterojunctions such as intermolecular charge transfer, phase separation, and aggregation behaviors to tune the material efficiency, ${ }^{41,42}$ we focused our study in that direction. Additionally, 
AFM, SEM, and special fluorescent microscopic techniques were used to understand the morphological behaviors at different compositions and how it influenced the photocatalytic efficacy. Special emphasis was given to understand why only a specific composition ratio caused a regular patterning of P3HT-PCBM aggregate, in turn affecting the photocatalytic efficiency significantly. Finally, a comparison of results of photocatalytic efficiency at different compositions, in light of aggregation-induced enhancement of photovoltaic performance ${ }^{4}$ was briefly undertaken.

We prepared P3HT: PCBM films with different weight fractions of P3HT polymer and PCBM (table S1) (weight percent in terms of PCBM contents) such as 1:0 (0\%), 1:0.25 (20\%), 1:0.5 (33.3\%), $1: 0.75(42.9 \%), 1: 1(50 \%), 0.75: 1(57.1 \%), 0.5: 1(66.7 \%)$ and $0.25: 1$ $(80 \%)$ to evaluate their impact on surface morphology and photocatalytic efficiency. The P3HT-PCBM film photocatalysts were subjected to photocatalytic degradation of Rhodamine B (RhB) dye under different experimental conditions. In order to understand the spectroscopic and surface characteristics of polymer composite films effectively various characterization techniques using UVVisible spectrophotometer, Fluorescence spectrophotometer, XRD, SEM, AFM, fluorescence microscope, and contact angle measurements were used.

Particularly, the fluorescence microscope is useful since one of the components (P3HT) is fluorescence active while the other component (PCBM) is not (ESI Figure S1(a) and S1(e) respectively). The P3HT film alone shows bright red emission without any specific surface features due to the relaxation of excitons which generates luminescence in the visible region. ${ }^{43}$ On the other hand, PCBM film alone did not show any emission in the same wavelength of excitation. For P3HT-PCBM blends, from $1: 0.25$ to $1: 1$ ratio film no significant change was observed in fluorescent surface morphology compared to P3HT film (ESI Figure S1(b-d) and Figure 2(a). But interestingly, for P3HT-PCBM films of ratio $0.75: 1,0.5: 1$, and 0.25:1, we observed red emitted fluorescent images with distinct surface morphology due to the varying PCBM contents (Figure 2(b), 2(c) and 2(d) respectively). In the case of $0.75: 1$ and $0.5: 1$ ratio, the film with spherical aggregates of submicron size consisting of P3HT-PCBM was clearly observed with several fibers wrapped around the aggregates. However, for the 0.5:1 ratio, the sizes of spherical features are high and regular, compared to the $0.75: 1$ ratio suggesting that the aggregation of P3HT-PCBM particles is more in this particular film. The film with a $0.25: 1$ (Figure 2(d)) ratio shows distinguishable red emitted domains without any spherical features due to low contents of P3HT. The regular patterning for special compositions of 0.75:1 and 0.5:1 was clearly visible in 3D movies (3-D view) of Z-stacked images (Figure 3, videos in ESI, movie S1a, movie S1b, and movie S1c).
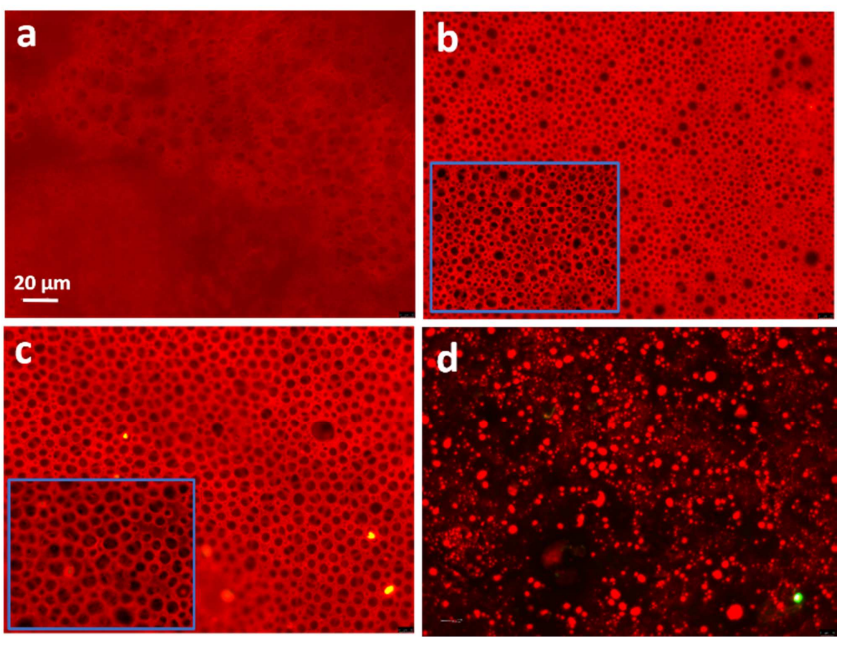

Figure 2. Fluorescence microscopic images of P3HT-PCBM films with different ratios (a) $1: 1$, (b) $0.75: 1$, (c) $0.5: 1$, and (d) $0.25: 1$; Inset: corresponding Z-stacked images

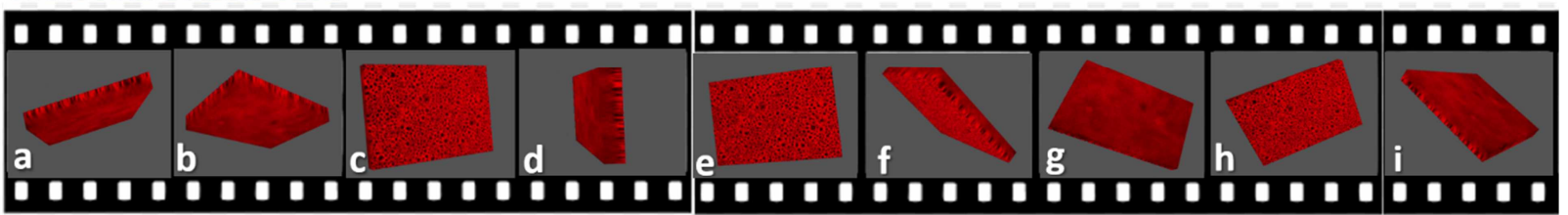
0.5:1 ratio $\mathrm{P} 3 \mathrm{HT}: \mathrm{PCBM}$

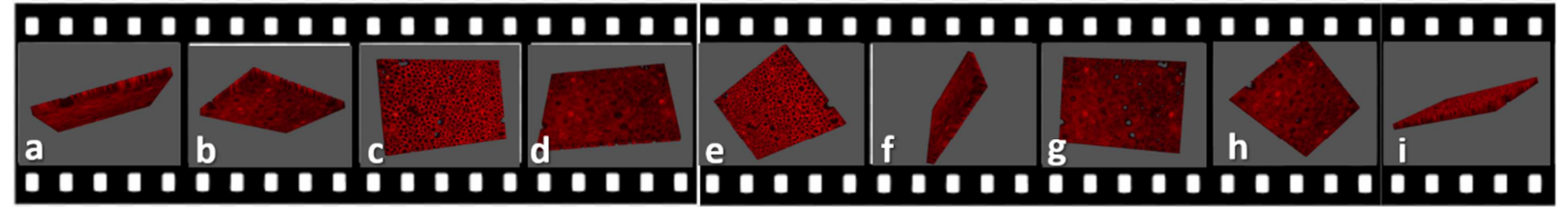
0.25:1 ratio $\mathrm{P} 3 \mathrm{HT}: \mathrm{PCBM}$

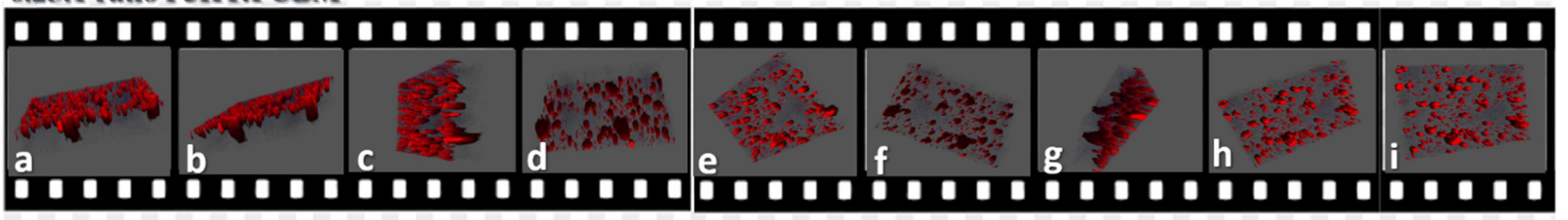

Figure 3. Snapshots of movies (ESI) of 3-d view of P3HT-PCBM films under fluorescence microscope (Z-stacked images from different angles a-i) 
In a similar trend, in absorption and fluorescence spectroscopic studies, (ESI Figure S3, S4 and S5) while the intensity of the emission decreased gradually by increasing the amount of PCBM, possibly because of intermolecular charge transfer, an increase with respect to control experiment was observed for the ratio of $0.5: 1$, possibly due to increased aggregation. ${ }^{41,} 42$ The morphological characteristics were also visible by SEM and AFM for the specific composition ratio of $0.5: 1$, although unlike fluorescence images, regular patterning was not clearly visible. The SEM images of P3HT films shows irregular shaped bright color domain particles without any features (ESI Figure S6). ${ }^{44}$ The film with a 1:1 ratio of P3HTPCBM exhibits the dispersion of polymer domains due to the diffusion of PCBM in a polymer matrix (Figure 4(a)). But in the case of a ratio of 0.5: 1 for P3HT-PCBM film (Figure 4(b)), it shows the better spatial distribution of donor and acceptor of P3HT-PCBM domains attributed to the crystallization of $\mathrm{P} 3 \mathrm{HT}$ polymers. ${ }^{45}$
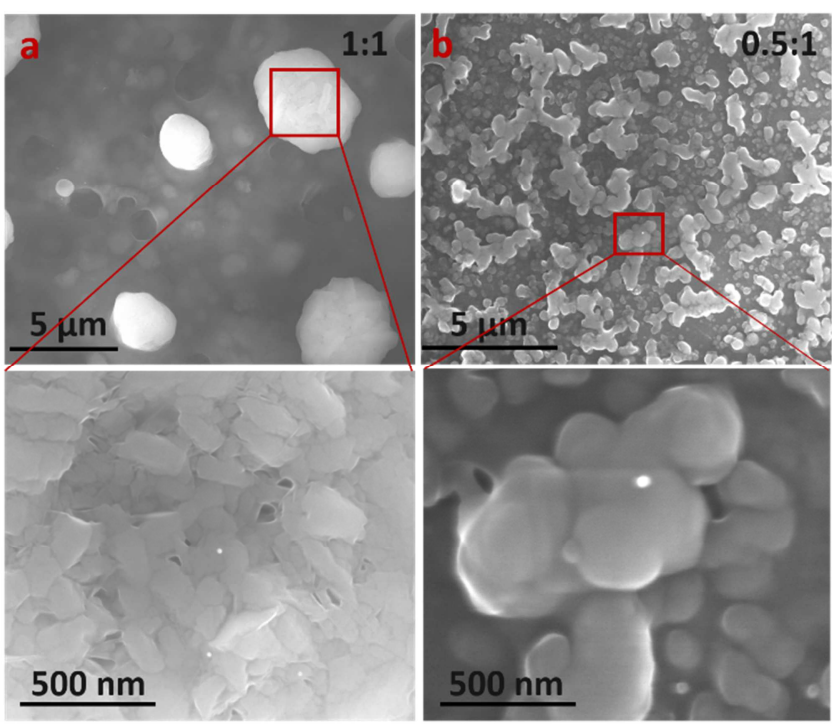

Figure 4. SEM images of P3HT-PCBM films in a different ratio (a) $1: 1$ and (b) $0.5: 1$; Corresponding zoomed images have been shown below

The AFM topographic images of P3HT-PCBM films are depicted in Figure 5, which also provided information about surface roughness. The surface roughness property of photoactive layers is an important parameter for efficiency of photovoltaics as well as photocatalysis. In this case, it is clearly observed that the pristine P3HT and P3HTPCBM film with a 1:1 ratio has smoother surfaces with surface roughness (RMS) values of $2.98 \mathrm{~nm}$ and $2.08 \mathrm{~nm}$ respectively. D.Yang et al and F.Zhang et al noted that suppressing the surface roughness leads to the improvement of fill factor and open circuit voltage values in photovoltaics devices. ${ }^{46,47}$ Along the same line, for photocatalysis, the high surface roughness can expose a large surface area to enhance the catalytic efficiency ${ }^{48}$ it was clearly observed from 3D images (Figure 5 and ESI Figure S7) that, the film with 0.5:1 ratio (Figure 5(b) and 5(d)) appears to possess more surface roughness $(34.8 \mathrm{~nm})$ than the other films with $1: 1$ ratio $(2.08 \mathrm{~nm})$, pristine P3HT (2.98 nm) and pristine PCBM (18.45 nm) (Figure 5(a) and 5(c)) to facilitate the enhanced catalytic efficiency of particular P3HT-PCBM film.
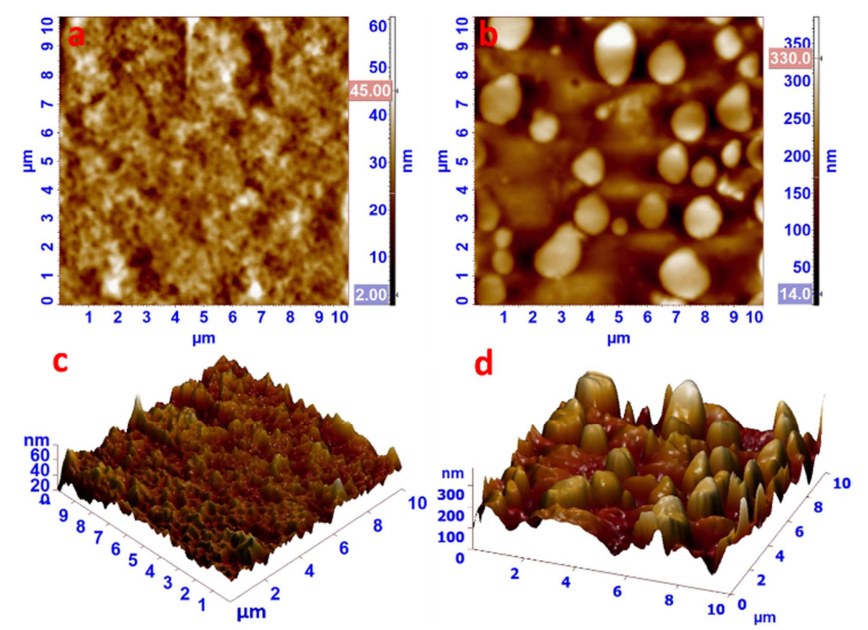

Figure 5. AFM micrographs of P3HT-PCBM films with ratio (a) 1:1 and (b) $0.5: 1$; (c) and (d) corresponding 3-D views

In order to understand the microstructure of $\mathrm{P} 3 \mathrm{HT}$ polymers by changing the PCBM loads in P3HT-PCBM blends, we performed the X-ray diffraction analysis (Figure 6(a), Figure S8 and ESI table $\mathrm{S} 2$ ). The pristine $\mathrm{P} 3 \mathrm{HT}$ polymer film shows two sets of diffraction patterns due to the lamellar stacking of P3HT backbones $\left(5.4^{\circ}(100)\right.$, $\left.11.03^{\circ}(200), 16.3^{\circ}(300)\right)$ and $\pi-\pi$ stacking of polythiophene $\left(23.4^{\circ}\right.$ $(010)) .{ }^{49}$ Chen et al, observed that the crystallinity of P3HT in P3HT-PCBM films was decreased by increasing the PCBM concentration. ${ }^{17}$ In our case also (1:1 ratio) similar observations were noticed with the reduction of peak intensity of P3HT peak at $10.57^{\circ}$ (200 plane). In the case of P3HT-PCBM film with a 0.5:1 ratio, the increment of peak intensity (1336) of P3HT peak at $10.53^{\circ}$ (200 plane) was observed compared to 1:1 ratio (855) (Figure 6(a) inset picture) indicating the high crystallinity due to the alignment of P3HT polymers induced by PCBM molecules of particular concentration.This property can influence the transportation of charges as well as catalytic efficiency.

The surface wettability of P3HT-PCBM films with different ratios was studied by a water contact angle meter and represented in Figure 6(b) and ESI Figure S9. It can be noted that pure P3HT (1:0) and $\operatorname{PCBM}(0: 1)$ exhibit a contact angle of $106.4^{\circ}$ and $83.6^{\circ}$ respectively. These values indicated that PCBM has high surface energy to exhibit hydrophilic character resulting from the presence of polar ester group whereas P3HT possesses hydrophobic nature due to the presence of the alkyl chains and thiophene rings. In this context, it may be noted that J.Wang et al reported that high catalytic efficiency was achieved by reducing hydrophobicity $\left(86.6^{\circ}\right)$ to enhance the surface contact between dye molecules and catalyst sites. ${ }^{50}$ In the same line, we observed that at a ratio of 0.5:1 (P3HT-PCBM) film possessed greater hydrophilic property due to the high contents of PCBM to introduce better catalytic activity. 


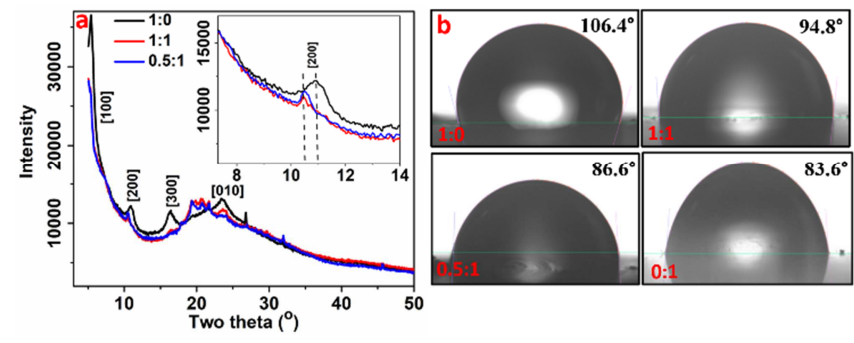

Figure 6. (a) XRD pattern of P3HT-PCBM films; (b) Water droplet images and contact angle values of P3HT-PCBM films with different ratio

The photocatalytic degradation study of rhodamine B dye (model organic pollutant) was performed using different weight fractions of P3HT-PCBM film photocatalysts under natural sunlight under different experimental conditions described in ESI (table S3, S4 and S5). Initially, we attempted with a 1:1 ratio of P3HT-PCBM film because this particular ratio blend has been extensively explored in P3HT-PCBM based photovoltaic device fabrication. ${ }^{10}$ Figure 7(a) indicates the percentage removal of dye in different initial concentration (1 to $6 \mathrm{ppm}$ ), Consequently for $1 \mathrm{ppm}, 2 \mathrm{ppm}$, and 6 ppm dye concentration $76 \%, 52 \%$, and $30 \%$ degradation has happened respectively after 2 hours of sunlight illumination using P3HT-PCBM film (1:1 ratio)photocatalyst. We also carried out the study of dye degradation without the usage of film catalyst as a control experiment to observe around 15\% degradation implicating the self-degradation of RhB dye. Subsequently, we carried out the dye degradation studies using of P3HT-PCBM films with different weight fractions $(1: 0,1: 0.25,1: 0.5,1: 0.75,1: 1,0.75: 1,0.5: 1$, and $0.25: 1$ ) with fixed dye concentration ( $2 \mathrm{ppm}$ ) for 2 hours irradiation. Interestingly, as seen from Figure 7(b), minor changes in the catalytic activities of P3HT-PCBM films generally observed with the change in P3HT amount from the ratio of 1:0 to 1:1 ratios (minor decrease generally). However, from $0.75: 1$ ratio $(77.8 \%)$, the catalytic activity started to increase significantly upto $0.5: 1$ ratio (95.1\%), plausibly due to more effective charge separations. Further, for $0.25: 1$ ratio very low catalytic activity (36.3\%) was observed plausibly due to inefficiency in generation of charges at very low concentration of donor molecules. The observations were corroborated from the photographic images of dye solution after exposures (Figure 7(b), inset picture a-h). Further, we studied the degradation rate using P3HT-PCBM (1:1) films by changing irradiation time (from $0 \mathrm{~min}$ to $180 \mathrm{~min}$ ) with $2 \mathrm{ppm}$ concentration of dye solution as depicted in Figure 7(c). It indicated that the removal of dye was increased gradually upto $76 \%$ after 180 minutes of irradiation. Figure 7(d) indicates that there was a gradual decrease in the UV-VIS absorbance of dye solution with increased time of irradiation. Besides, we obtained the high rate constant values $(0.007$ $\min ^{-1}$ ) from kinetic study of dye degradation (ESI Figure S10). Further, we studied the recyclability performance of P3HT-PCBM (0.5:1 ratio) film upto three cycles (ESI Figure S12, table S6) and we observed the catalytic efficiency of $1^{\text {st }}, 2^{\text {nd }}$, and $3^{\text {rd }}$ cycles were $95.1 \%, 93.8 \%$ and $79.8 \%$ respectively.

The high efficacy of dye degradation at a specific concentration ratio may be attributed to similar mechanism of photovoltaics where PCBM acts as an efficient acceptor molecule, and P3HT acts as a donor molecule, to generate the electrons and holes which can facilitate to produce various active radical species for dye degradation Importantly, photocatalytic activities were best for the ratio of $0.5: 1$, when regular patterning of P3HT-PCBM was also observed from various microscopic images (vide infra). This results reveal that the light absorption and exciton dissociation processes for P3HT-PCBM system is high in the case of 0.5:1 ratio. It can enhance the charge transportation from donor to acceptor and reduce charge carrier recombination rate leading to generation of more active radical
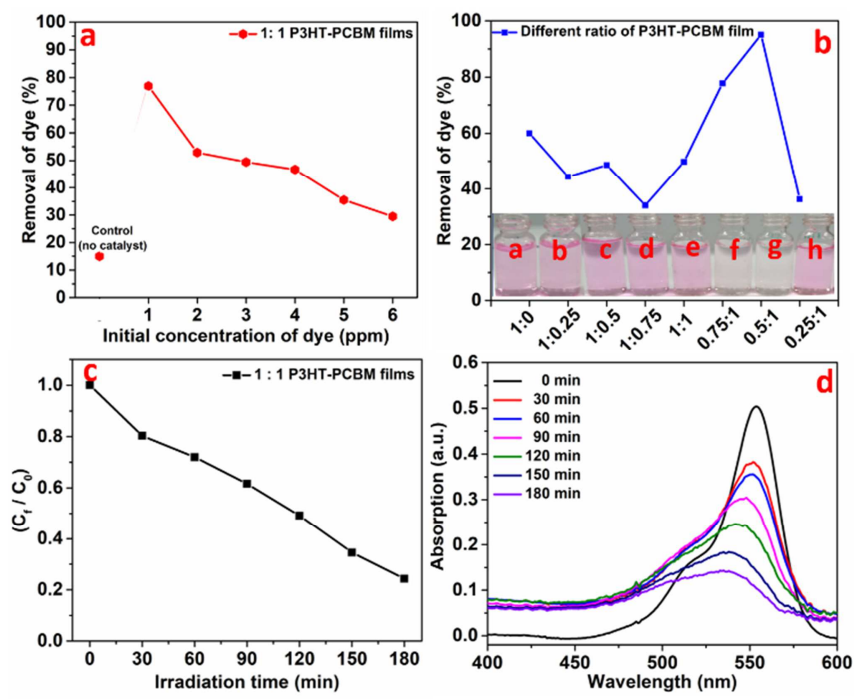

Figure 7. (a) percentage removal of dye in a different initial concentration of dye using 1:1 ratio of P3HT-PCBM in the films; (b) percentage removal of dye with different ratio of P3HT-PCBM films (inset picture: dye solution after irradiation); (c) removal of dye interms of $\left[\mathrm{C}_{\mathrm{f}}\right] /\left[\mathrm{C}_{0}\right]$ ratio in a different time interval of irradiation; (d) UV-Visible spectra of dye solution after irradiation in a different time.

In conclusion, we have demonstrated that surfaces with P3HTPCBM, can be used very effectively as a reusable metal free photocatalytic "Chip" for the degradation of polluting dyes in aqueous phase. However, the best efficacy in dye degradation is achieved with the composition ratio of 0.5:1 P3HT-PCBM, contrary to the composition ratio of $1: 1$ which showed the best efficiency in the case of bulk heterojunction solar cell devices. This was attributed to distinct morphology for the ratio of $0.5: 1$ as observed in fluorescence microscopic images and the movies in 3-D views. The observation can also be useful in future to understand the importance of ratios of donor and acceptor molecules in bulk heterojunction solar cell devices although a more detailed study is required to establish whether photocatalytic dye degradation phenomenon can be used as a model to study photovoltaic device performance.

\section{ASSOCIATED CONTENT}

\section{Supporting Information}

P3HT-PCBM film characterization and Detailed experimental procedure for photocatalytic dye degradation.

\section{AUTHOR INFORMATION}

\section{Corresponding author}

Email: debasis@clri.res.in 


\section{ACKNOWLEDGEMENTS}

Financial support from MLP13 is gratefully acknowledged. We are thankful to CATERS Department of CLRI for assisting with AFM analysis. We acknowledged Nanotechnology Research Centre (NRC), SRMIST for providing the XRD and FESEM analysis. CSIR-CLRI communication number is 1589 .

Notes:

The authors declare no competing financial interest.

(1) Lu, L.; Zheng, T.; Wu, Q.; Schneider, A. M.; Zhao, D.; Yu L. Recent Advances in Bulk Heterojunction Polymer Solar Cells. Chem. Rev. 2015, 115, 12666-12731.

(2) Samanta, D.; Sarkar, A. Immobilization of biomacromolecules on self-assembled monolayers: methods and sensor applications. Chem. Soc. Rev. 2011, 40, 2567-2592.

(3) Murugan, P.; Krishnamurthy, M.; Jaisankar, S. N.; Samanta, D.; Mandal, A. B. Controlled decoration of the surface with macromolecules: polymerization on a self-assembled monolayer (SAM). Chem. Soc. Rev. 2015, 44, 3212-3243.

(4) Li, L.; Lu, G.; Yang, X. Improving performance of polymer photovoltaic devices using an annealing-free approach via construction of ordered aggregates in solution. J. Mater. Chem. C 2008, 18, 1984-1990.

(5) Kajiya, D.; Saitow, K.-I. Si-nanocrystal/P3HT hybrid films with a 50- and 12-fold enhancement of hole mobility and density: films prepared by successive drop casting. Nanoscale 2015, 7, 15780-15788.

(6) Ha, Y. E.; Jo, M. Y.; Park, J.; Kang, Y.-C.; Yoo, S. I.; Kim, J. H. Inverted Type Polymer Solar Cells with Self-Assembled Monolayer Treated ZnO. J. Phys. Chem. C 2013, 117, 26462652.

(7) Dang, M.-T.; Hirsch, L.; Wantz, G. P3HT:PCBM, best seller in polymer photovoltaic research. Adv. Mater 2011, 23, 35973602 .

(8) Gonzalez, D. M.; Korstgens, V.; Yao, Y.; Song, L.; Santoro, G.; Roth, S. V.; Muller-Buschbaum, P. Improved Power Conversion Efficiency of P3HT:PCBM Organic Solar Cells by Strong Spin-Orbit Coupling-Induced Delayed Fluorescence. Adv. Energy Mater. 2015, 5, DOI: 10.1002/aenm.201401770.

(9) Kadem, B.; Cranton, W.; Hassan, A. Metal salt modified PEDOT:PSS as anode buffer layer and its effect on power conversion efficiency of organic solar cells. Org. Electron. 2015, 24, 73-79.

(10) Berger, P. R.; Kim, M. Polymer solar cells: P3HT:PCBM and beyond. J. Renew. Sustain. Energy 2018, 10, DOI: 10.1063/1061.5012992.

(11) Casalegno, M.; Kotowski, D.; Bernardi, A.; Luzzati, S.; Po, R.; Raos, G. The effect of donor content on the efficiency of P3HT:PCBM bilayers: optical and photocurrent spectral data analyses. Phys. Chem. Chem. Phys. 2015, 17, 2447-2456.

(12) Liu, F.; Chen, D.; Wang, C.; Luo, K.; Gu, W.; Briseno, A. L.; Hsu, J. W. P.; Russell, T. P. Molecular Weight Dependence of the Morphology in P3HT:PCBM Solar Cells. ACS Appl. Mater. Interfaces 2014, 6, 19876-19887.

(13) Lioudakis, E.; Alexandrou, I.; Othonos, A. Ultrafast Dynamics of Localized and Delocalized Polaron Transitions in

\section{References}

P3HT/PCBM Blend Materials: The Effects of PCBM Concentration. Nanoscale Research Letters 2009, 4, 1475-1480.

(14) Bavel, S.; BÃrenklau, M.; With, G.; Hoppe, H.; Loos, J. P3HT/PCBM Bulk Heterojunction Solar Cells: Impact of Blend Composition and 3D Morphology on Device Performance. Adv. Funct. Mater. 2010, 20, 1458-1463.

(15) Kadem, B.; Hassan, A. The effect of fullerene derivatives ratio on P3HT-based organic solar cells. Energy Procedia 2015, 74, 439-445.

(16) Chaudhary, N.; Chaudhary, R.; Kesari, J.; Patra, A. Effect of composition ratio of P3HT:PC61 BM in organic solar cells: optical and morphological properties. Mater. Res. Innov. 2017, $22,1-5$.

(17) Chen, F.-C.; Ko, C.-J.; Wu, J.-L.; Chen, W.-C. Morphological study of P3HT:PCBM blend films prepared through solvent annealing for solar cell applications. Sol. Energy Mater. Sol. Cells 2010, 94, 2426-2430.

(18) Chaudhary, N.; Chaudhary, R.; Kesari, J. P.; Patra, A. Effect of composition ratio of $\mathrm{P} 3 \mathrm{HT}: \mathrm{PC}_{61} \mathrm{BM}$ in organic solar cells: optical and morphological properties. Mater. Res. Innov. 2018, 22, 282-286.

(19) Vaynzof, Y.; Kabra, D.; Zhao, L.; Chua, L. L.; Steiner, U.; Friend, R. H. Surface-Directed Spinodal Decomposition in Poly[3-hexylthiophene] and C61-Butyric Acid Methyl Ester Blends. ACS Nano 2011, 5, 329-336.

(20) Parnell, A. J.; Cadby, A. J.; Mykhaylyk, O. O.; Dunbar, A. D. F.; Hopkinson, P. E.; Donald, A. M.; Jones, R. A. L. Nanoscale Phase Separation of P3HT PCBM Thick Films As Measured by Small-Angle X-ray Scattering. Macromolecules 2011, 44, 6503-6508.

(21) Liu, J.; Cheng, B.; Yu, J. A new understanding of the photocatalytic mechanism of the direct Z-scheme $\mathrm{g}-\mathrm{C}_{3} \mathrm{~N}_{4} / \mathrm{TiO}_{2}$ heterostructure. Phys. Chem. Chem. Phys. 2016, 18, 3117531183.

(22) Ghosh, S.; Kouam Ã, N.; Ramos, L.; Remita, S.; Dazzi, A.; Deniset-Besseau, A.; Beaunier, P.; Goubard, F.; Aubert, P.-H.; Remita, H. Conducting polymer nanostructures for photocatalysis under visible light. Nat. Mater. 2015, 14, 1-7.

(23) Floresyona, D.; Goubard, F.; Aubert, P.-H.; Lampre, I.; Mathurin, J.; Dazzi, A.; Ghosh, S.; Beaunier, P.; Brisset, F.; Remita, S.; Ramos, L.; Remita, H. Highly active poly(3hexylthiophene) nanostructures for photocatalysis under solar light. Applied Catalysis B: Environmental 2017, 209, 23-32.

(24) Vellaichamy, B.; Periakaruppan, P. Synergistic Combination of a Novel Metal-Free Mesoporous Band-GapModified Carbon Nitride Grafted Polyaniline Nanocomposite for Decontamination of Refractory Pollutant. Ind. Eng. Chem. Res. 2018, 57, 6684-6695. 
(25) Janovak, L.; Dernovics, A.; Merai, L.; Deak, A.; Sebok, D.; Csapo, E.; Varga, A.; Dekany, I.; Janaky, C. Microstructuration of poly(3-hexylthiophene) leads to bifunctional superhydrophobic and photoreactive surfaces. Chem. Commun. 2018, 54, 650-653.

(26) Bhowmik, S.; Jadhav, R. G.; Das, A. K. Nanoporous Conducting Covalent Organic Polymer (COP) Nanostructures as Metal-Free High Performance Visible-Light Photocatalyst for Water Treatment and Enhanced CO2 Capture. J. Phys. Chem. C 2018, 122, 274-284.

(27) Murugan, P.; Ramar, P.; Mandal, A. B.; Samanta, D. Investigating the Photocatalytic Performances of Nanocomposites Containing Narrow-band-gap Copolymers and ZnO. ChemistrySelect 2019, 4, 14214-14221.

(28) Kamat, P. V. Semiconductor Surface Chemistry as Holy Grail in Photocatalysis and Photovoltaics. Acc. Chem. Res. 2017, 50, 527-531.

(29) Anwer, H.; Mahmood, A.; Lee, J.; Kim, K.-H.; Park, J.-W.; Yip, A. C. K. Photocatalysts for degradation of dyes in industrial effluents: Opportunities and challenges. Nano Res. 2019, 12, 955972 .

(30) Le Bahers, T.; Racrat, M.; Sautet, P. Semiconductors Used in Photovoltaic and Photocatalytic Devices: Assessing Fundamental Properties from DFT. J. Phys. Chem. C 2014, 118, 5997-6008.

(31) Fuentes, M.; Vivar, M.; Scott, J.; Srithar, K.; Skryabin, I. Results from a first autonomous optically adapted photocatalyticphotovoltaic module for water purification. Sol. Energy Mater. Sol. Cells 2012, 100, 216-225.

(32) Mukhopadhyay, L.; Mondal, M.; Rai, V. Photovoltaics and Photocatalysis: Promising Applications of Lanthanide doped Luminescent Materials. INT J TECHNOL MANAGE 2016, 2, 811.

(33) Gulce, H.; Eskizeybek, V.; Haspulat, B.; Sari, F.; Gulce, A.; Avci, A. Preparation of a New Polyaniline/CdO Nanocomposite and Investigation of Its Photocatalytic Activity: Comparative Study under UV Light and Natural Sunlight Irradiation. Ind. Eng. Chem. Res. 2013, 52, 10924-10934.

(34) Yao, K.; Chen, L.; Chen, Y.; Li, F.; Wang, P. Influence of water-soluble polythiophene as an interfacial layer on the P3HT/PCBM bulk heterojunction organic photovoltaics. $J$. Mater. Chem. A 2011, 21, 13780-13784.

(35) Murugan, P.; Raghavendra, V.; Chithiravel, S.; Krishnamoorthy, K.; Mandal, A. B.; Subramanian, V.; Samanta, D. Experimental and Theoretical Investigations of Different Diketopyrrolopyrrole-Based Polymers. ACS Omega 2018, 3, 11710-11717.

(36) Koster, L. J. A.; Mihailetchi, V. D.; Blom, P. W. M. Ultimate efficiency of polymer/fullerene bulk heterojunction solar cells. Appl. Phys. Lett. 2006, 88, doi: 10.1063/1061.2181635.

(37) Scharber, M. C.; Sariciftci, N. S. Efficiency of bulkheterojunction organic solar cells. PROG POLYM SCI 2013, 38, 1929-1940.

(38) Krishnamurthy, M.; Krishnamoorthy, K.; Arulkashmir, A.; Raghavendra, V.; Murali, A.; Jaisankar, S. N.; Murugan, P.; 1
Gurusamy-Thangavelu, S. A.; Nasar, A. S.; Mandal, A. B.; Samanta, D. "Click" polymerization: A convenient strategy to prepare designer fullerene materials. Materials \& Design 2016, $108,34-41$.

(39) Chen, D.; Nakahara, A.; Wei, D.; Nordlund, D.; Russell, T. P. P3HT/PCBM Bulk Heterojunction Organic Photovoltaics: Correlating Efficiency and Morphology. Nano Lett. 2011, 11, 561-567.

(40) Kar, P.; Maji, T. K.; Patwari, J.; Pal, S. K. Can a light harvesting material be always common in photocatalytic and photovoltaic applications? Mater. Chem. Phys 2017, 200, 70-77.

(41) Razzell-Hollis, J.; Limbu, S.; Kim, J.-S. Spectroscopic Investigations of Three-Phase Morphology Evolution in Polymer: Fullerene Solar Cell Blends. J. Phys. Chem. C 2016, 120, 1080610814.

(42) Tsoi, W. C.; Spencer, S. J.; Yang, L.; Ballantyne, A. M.; Nicholson, P. G.; Turnbull, A.; Shard, A. G.; Murphy, C. E.; Bradley, D. D. C.; Nelson, J.; Kim, J.-S. Effect of Crystallization on the Electronic Energy Levels and Thin Film Morphology of P3HT:PCBM Blends. Macromolecules 2011, 44, 2944-2952.

(43) Vohra, V.; Yunus, S.; Attout, A.; Giovanella, U.; Scavia, G.; Tubino, R.; Botta, C.; Bolognesi, A. Bifunctional microstructured films and surfaces obtained by soft lithography from breath figure arrays. Soft Matter 2009, 5, 1656-1661.

(44) Hoppe, H.; Niggemann, M.; Winder, C.; Kraut, J.; Hiesgen, R.; Hinsch, A.; Meissner, D.; Sariciftci, N. S. Nanoscale Morphology of Conjugated Polymer/Fullerene-Based BulkHeterojunction Solar Cells. Adv. Funct. Mater. 2004, 14, 10051011.

(45) Rajasekar, S.; Fortin, P.; Holdcroft, S. Photocathodic hydrogen evolution from catalysed nanoparticle films prepared from stable aqueous dispersions of P3HT and PCBM. Synth. Met. 2018, 247, 10-17.

(46) Yang, D.; Jang, J. G.; Lim, J.; Lee, J.-k.; Kim, S. H.; Hong, J.-I. Correlations of Optical Absorption, Charge Trapping, and Surface Roughness of $\mathrm{TiO}_{2}$ Photoanode Layer Loaded with Neat Ag-NPs for Efficient Perovskite Solar Cells. ACS Appl. Mater. Interfaces 2016, 8, 21522-21530.

(47) Ma, Z.; Tang, Z.; Wang, E.; Andersson, M. R.; Inganas, O.; Zhang, F. Influences of Surface Roughness of $\mathrm{ZnO}$ Electron Transport Layer on the Photovoltaic Performance of Organic Inverted Solar Cells. J. Phys. Chem. C 2012, 116, 24462-24468.

(48) Yang, J. L.; An, S. J.; Park, W. I.; Yi, G.-C.; Choi, W. Photocatalysis Using $\mathrm{ZnO}$ Thin Films and Nanoneedles Grown by Metal-Organic Chemical Vapor Deposition. Adv. Mater. 2004, 16, 1661-1664.

(49) Nieuwendaal, R. C.; Snyder, C. R.; DeLongchamp, D. M. Measuring Order in Regioregular Poly(3-hexylthiophene) with Solid-State ${ }^{13}$ C CPMAS NMR. ACS Macro Lett. 2014, 3, 130135.

(50) Wang, J.; Mao, B.; Gole, J. L.; Burda, C. Visible-lightdriven reversible and switchable hydrophobic to hydrophilic nitrogen-doped titania surfaces: correlation with photocatalysis. Nanoscale 2010, 2, 2257-2261. 